\title{
Impact of pharmacist administration of influenza vaccines on uptake in Canada
}

\author{
Sarah A. Buchan MSc, Laura C. Rosella PhD, Michael Finkelstein MD, David Juurlink MD PhD, Jennifer Isenor PharmD, \\ Fawziah Marra PharmD, Anik Patel MHA, Margaret L. Russell MD PhD, Susan Quach MSc, Nancy Waite PharmD, \\ Jeffrey C. Kwong MD MSc; for the Public Health Agency of Canada/Canadian Institutes of Health Research Influenza \\ Research Network (PCIRN) Program Delivery and Evaluation Group
}

Cite as: CMAJ 2017 January 30;189:E146-52. doi: 10.1503/cmaj.151027

\begin{abstract}
BACKGROUND: Uptake of influenza vaccination in Canada remains suboptimal despite widespread public funding. To increase access, several provinces have implemented policies permitting pharmacists to administer influenza vaccines in community pharmacies. We examined the impact of such policies on the uptake of seasonal influenza vaccination in Canada.
\end{abstract}

METHODS: We pooled data from the 2007-2014 cycles of the Canadian Community Health Survey $(n=481526)$. To determine the impact of influenza vaccine administration by pharmacists, we estimated the prevalence ratio for the association between the presence of a pharmacist policy and individual-level vaccine uptake using a modified Poisson regression model (dependent variable: vaccine uptake) with normalized weights while controlling for numerous health and sociodemographic factors.

RESULTS: Across all survey cycles combined, $28.8 \%$ of respondents reported receiving a seasonal influenza vaccine during the 12 months before survey participation. Introduction of a policy for pharmacist administration of influenza vaccine was associated with a modest increase in coverage $(2.2 \%)$ and an individual's likelihood of uptake (adjusted prevalence ratio $1.05,95 \%$ confidence interval 1.02-1.08).

INTERPRETATION: Uptake of influenza immunization was modestly increased in Canadian jurisdictions that allowed pharmacists to administer influenza vaccines.

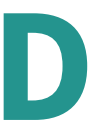

espite widespread public funding for influenza vaccination in Canada, either for high-risk groups or the entire population depending on the province or territory, uptake remains suboptimal. ${ }^{1}$ Numerous factors influence an individual's decision to be vaccinated, and although many of these relate to health beliefs and risk-benefit perceptions that can be challenging to address, ease of access to vaccination may play a role. ${ }^{2-5}$

Influenza vaccines are primarily administered by nurses and physicians in Canada, but several provinces have recently implemented policies permitting administration by pharmacists (Table 1). ${ }^{6}$ Community pharmacists who have been authorized to administer influenza vaccines could help to overcome issues with accessibility given their ubiquitous distribution, extended working hours, walk-in policies and availability to people without a primary care provider. ${ }^{7-9}$

In the United States, all states allow trained pharmacists to administer vaccines. ${ }^{10}$ This has enhanced patient access as perceived by patients, ${ }^{11}$ elicited support from prospective vaccinees ${ }^{12}$ and increased vaccine coverage. ${ }^{13,14}$ Steyer and colleagues ${ }^{14}$ com- pared influenza vaccine coverage in the US from 1995 to 1999 and found an absolute increase of $10.7 \%$ among adults aged 65 years and older in states where pharmacists could give the vaccine (from $57.7 \%$ to $68.4 \%$ ), as compared with an increase of $3.5 \%$ in states that did not have such a policy at the time of the study (from $61.2 \%$ to $64.7 \%$ ). Grabenstein and colleagues ${ }^{13}$ found a significant increase in influenza vaccination among younger adults. Improvements in influenza vaccine coverage consistent with a pharmacist vaccinator effect have also been observed in rural populations in the US ${ }^{15}$ and in populations in Japan. ${ }^{16}$

In Canada, patients have expressed support for pharmacistadministered vaccination, ${ }^{17}$ and pharmacists have indicated strong interest in expanding their scope of practice. ${ }^{18} \mathrm{~A}$ Canadian pilot study suggested that $80 \%$ of influenza vaccine recipients prefer getting their vaccine at pharmacy-based clinics. ${ }^{7}$ However, it is unknown whether these findings translate to populationbased increases in vaccine coverage, particularly given changes over time in other factors such as removal of financial barriers to influenza immunization through public funding. We sought to de- 
termine the impact of regulatory changes allowing pharmacists to provide influenza vaccines on the uptake of seasonal influenza immunization in Canada.

\section{Methods}

\section{Study population}

We used nationally representative data from the 2007-2014 cycles of the Canadian Community Health Survey. This cross-sectional survey has been conducted by Statistics Canada through telephone and in-person interviews annually since 2007, covering a range of questions related to health status, health care utilization and determinants of health. ${ }^{19}$ Using a multistage stratified cluster design, the survey includes a sample of about 65000 respondents aged 12 years and older in each cycle. The survey excludes people living on reserves and other Aboriginal settlements, full-time members of the Canadian military, people in institutions and residents in remote health regions in Quebec (all representing < $3 \%$ of the population). ${ }^{19}$ The response rate declined across survey cycles, from $77.6 \%$ to $65.6 \% .^{20}$

Our study was approved by the Ethics Review Board of Public Health Ontario.

\section{Definitions}

The dependent variable was self-reported influenza vaccination, determined through responses to the questions "Have you ever had a (seasonal) flu shot?" and "When did you have your last (seasonal) flu shot?" Individuals who reported receiving their last flu shot in the 12 months before the survey were considered immu-

Table 1: Timing of implementation of universal funding for influenza vaccination and policy permitting pharmacists to administer publicly funded influenza vaccines, by province/territory

\begin{tabular}{|c|c|c|}
\hline Province/territory & $\begin{array}{l}\text { Universal } \\
\text { funding }\end{array}$ & $\begin{array}{c}\text { Pharmacist } \\
\text { policy }\end{array}$ \\
\hline Newfoundland and Labrador & 2014 & 2014 \\
\hline Prince Edward Island & 2004 & 2014 \\
\hline Nova Scotia† & 2010 & 2013 \\
\hline New Brunswick $†$ & NA & 2010 \\
\hline Quebec & NA & NA \\
\hline Ontario $†$ & 2000 & 2012 \\
\hline Manitoba & 2010 & 2014 \\
\hline Saskatchewan & 2010 & 2015 \\
\hline Alberta & 2009 & 2009 \\
\hline British Columbia† & NA & 2009 \\
\hline Nunavut & 2005 & NA \\
\hline Northwest Territories & 2003 & NA \\
\hline Yukon & 1999 & NA \\
\hline \multicolumn{3}{|c|}{$\begin{array}{l}\text { Note: } \mathrm{NA} \text { = policy not available. } \\
\text { *Influenza vaccines are freely available for residents aged } 6 \mathrm{mo} \text { and older; in the Yukon, } \\
\text { the policy applies to residents } 18 \text { yr and older. } \\
\text { †Province with pharmacist policy in survey cycles analyzed. }\end{array}$} \\
\hline
\end{tabular}

nized. These respondents were also asked, "In which month did you have your last flu shot?" Those whose response matched the month of the survey date were then asked, "Was that this year or last year?" We considered respondents who reported receiving the vaccine during the same month as the survey date but in the preceding year as not immunized.

We constructed our primary independent variable - the ability for pharmacists to administer publicly funded influenza vaccines ("pharmacist policy") - based on province of residence and influenza season (Table 1). The start of the pharmacist policy was deemed to coincide with the start of the corresponding influenza season, defined as Oct. 1 to the following Sept. 30. Residents of Alberta and British Columbia from the 2009/10 influenza season onward, New Brunswick from 2010/11 onward, Ontario from 2012/13 onward and Nova Scotia from 2013/14 onward were classified as living in a jurisdiction with a pharmacist policy. Although Alberta introduced its policy in 2007, few pharmacists received certification for the 2007/08 and 2008/09 influenza seasons, and pharmacists were not part of the publicly funded program until $2009 / 10$. The available survey data do not cover subsequent influenza seasons when Manitoba, Newfoundland and Labrador, Prince Edward Island and Saskatchewan introduced their pharmacist policies.

We chose the following potential confounders for influenza vaccination a priori based on a review of the existing literature: age, sex, rural residence (population concentration $<1000$ and population density $<400$ per square kilometer), household income, education, marital status, immigration status, racial/ cultural group, self-reported health status, presence of chronic conditions (asthma, chronic obstructive pulmonary disease, heart disease, stroke, diabetes, cancer), body mass index, having a child less than 5 years old in the household, smoking status, receipt of the A/H1N1 2009 pandemic influenza vaccine (only for those surveyed in the 2010 cycle) and having a regular doctor. ${ }^{21-23}$ We also examined the impact of living in a jurisdiction that provides universal publicly funded influenza vaccination (based on province and influenza season) as a separate policy intervention from the pharmacist policies. ${ }^{21}$ To account for underlying temporal and provincial variations, we included influenza season and province as potential confounders.

\section{Statistical analysis}

We pooled individual-level responses from all survey cycles, with the final data set considered to represent the characteristics of the average population over the combined period of the survey cycles. ${ }^{24}$ Normalized weights were used to account for an unequal probability of selection in the sample. We used the CochranArmitage test to assess temporal trends in influenza vaccination by province. We used a weighted modified Poisson regression model to estimate the prevalence ratio for the association between the presence of a pharmacist policy and individual-level influenza vaccine uptake, ${ }^{25}$ controlling for sociodemographic information, health status and health behaviours associated with influenza vaccination. We chose this approach over logistic regression analysis because of the frequency of the outcome. ${ }^{26}$ We chose Quebec as the reference jurisdiction because it had the lowest ob- 
Table 2: Characteristics of the study population*

\begin{tabular}{|c|c|c|c|c|c|c|}
\hline \multirow[b]{2}{*}{ Characteristic } & \multicolumn{2}{|c|}{ Total sample } & \multicolumn{2}{|c|}{$\begin{array}{l}\text { Province or influenza season } \\
\text { with pharmacist policy }\end{array}$} & \multicolumn{2}{|c|}{$\begin{array}{l}\text { Province or influenza season } \\
\text { without pharmacist policy }\end{array}$} \\
\hline & No. (\%) & $\begin{array}{c}\text { Influenza } \\
\text { vaccination, \% }\end{array}$ & No. (\%) & $\begin{array}{c}\text { Influenza } \\
\text { vaccination, \% }\end{array}$ & No. (\%) & $\begin{array}{c}\text { Influenza } \\
\text { vaccination, \% }\end{array}$ \\
\hline Weighted sample & $481526(100)$ & 28.8 & $134250(27.9)$ & 30.4 & $347276(72.1)$ & 28.2 \\
\hline \multicolumn{7}{|l|}{ Age group, yr } \\
\hline $12-19$ & $52287(10.9)$ & 20.3 & $14078(10.5)$ & 22.6 & 38209 (11.0) & 19.4 \\
\hline $50-64$ & $116846(24.3)$ & 32.4 & 32933 (24.5) & 34.4 & $83913(24.2)$ & 31.7 \\
\hline$\geq 65$ & 74492 (15.5) & 61.8 & 20729 (15.4) & 62.9 & $53763(15.5)$ & 61.3 \\
\hline \multicolumn{7}{|l|}{ Sex } \\
\hline Male & $235935(49.0)$ & 25.7 & $66019(49.2)$ & 27.1 & 169916 (48.9) & 25.1 \\
\hline Female & $245591(51.0)$ & 31.7 & $68231(50.8)$ & 33.5 & $177360(51.1)$ & 31.1 \\
\hline Nova Scotia & $13411(2.8)$ & 42.1 & $1777(1.3)$ & 44.7 & $11634(3.4)$ & 41.7 \\
\hline New Brunswick & $10596(2.2)$ & 32.7 & $5515(4.1)$ & 35.6 & $5081(1.5)$ & 29.6 \\
\hline Quebec & $112554(23.4)$ & 22.5 & NA & NA & $112554(32.4)$ & 22.5 \\
\hline Ontario & 188273 (39.1) & 31.6 & $50328(37.5)$ & 31.3 & $137945(39.7)$ & 31.6 \\
\hline Manitoba & $16309(3.4)$ & 27.3 & NA & NA & $16309(4.7)$ & 27.3 \\
\hline Saskatchewan & $13793(2.9)$ & 28.3 & NA & NA & $13793(4.0)$ & 28.3 \\
\hline Alberta & $51815(10.8)$ & 28.1 & $34505(25.7)$ & 28.5 & $17310(5.0)$ & 27.4 \\
\hline British Columbia & $64006(13.3)$ & 29.6 & 42125 (31.4) & 29.5 & $21881(6.3)$ & 29.8 \\
\hline Nunavut & $307(0.1)$ & 34.9 & NA & NA & $307(0.1)$ & 34.9 \\
\hline Northwest Territories & $574(0.1)$ & 33.5 & NA & NA & $574(0.2)$ & 33.5 \\
\hline Diabetes & $29421(6.1)$ & 55.4 & 7934 (5.9) & 57.6 & $21487(6.2)$ & 54.6 \\
\hline Cancer & 9109 (1.9) & 54.3 & $2421(1.8)$ & 54.1 & $6688(1.9)$ & 54.4 \\
\hline \multicolumn{7}{|l|}{ Has regular doctor } \\
\hline Yes & 407405 (84.6) & 31.7 & $116191(86.5)$ & 33.0 & 291214 (83.9) & 31.2 \\
\hline No & $73611(15.3)$ & 12.6 & 17907 (13.3) & 13.6 & $55704(16.0)$ & 12.3 \\
\hline \multicolumn{7}{|l|}{ Influenza season } \\
\hline $2006 / 07$ & 44966 (9.3) & 31.8 & NA & NA & $44966(12.9)$ & 31.8 \\
\hline $2007 / 08$ & 60294 (12.5) & 29.6 & NA & NA & $60294(17.4)$ & 29.6 \\
\hline $2008 / 09$ & $60788(12.6)$ & 29.9 & NA & NA & $60788(17.5)$ & 29.9 \\
\hline $2009 / 10$ & $61070(12.7)$ & 25.6 & $14742(11.0)$ & 28.9 & $46328(13.3)$ & 24.5 \\
\hline $2010 / 11$ & 62221 (12.9) & 28.3 & $16254(12.1)$ & 29.4 & $45967(13.2)$ & 27.9 \\
\hline $2011 / 12$ & $62857(13.1)$ & 27.7 & $16698(12.4)$ & 29.1 & 46159 (13.3) & 27.2 \\
\hline $2012 / 13$ & $64668(13.4)$ & 27.6 & $42223(31.5)$ & 29.1 & $22445(6.5)$ & 24.7 \\
\hline $2013 / 14$ & $64662(13.4)$ & 30.6 & $44333(33.0)$ & 32.9 & $20329(5.9)$ & 25.5 \\
\hline \multicolumn{7}{|c|}{ Universal funding for influenza vaccines } \\
\hline Yes & $249139(51.7)$ & 31.2 & $86609(64.5)$ & 30.5 & $162530(46.8)$ & 31.7 \\
\hline No & $232387(48.3)$ & 26.1 & $47641(35.5)$ & 30.2 & $184746(53.2)$ & 25.1 \\
\hline
\end{tabular}

Note: $\mathrm{COPD}=$ chronic obstructive pulmonary disease, $\mathrm{NA}=$ pharmacist policy did not exist in province or influenza season studied

*Additional characteristics of the study population are available in Appendix 1 (available at www.cmaj.ca/lookup/suppl/doi:10.1503/cmaj.151027/-/DC1). 
served levels of influenza vaccination (thus all prevalence ratios comparing provinces and territories would be greater than 1) and because it was the only province that had not implemented either universal funding or a pharmacist policy (thus it was akin to a "no exposure" group). We assessed the model for interactions of pharmacist policy with age, chronic conditions and income.

We performed a sensitivity analysis in which we set introduction of the pharmacist policy in Alberta to the 2007/08 and 2008/09 seasons, as opposed to the $2009 / 10$ season.

A significance level of $p<0.05$ was used for all tests. We used SAS statistical software (version 9.3, SAS Institute Incorporated) for all analyses.

\section{Results}

After we excluded respondents with missing data on influenza vaccination ( $n=15764$ ), we had a total weighted sample of 481526 for our analysis (Table 2, and Appendix 1, available at www.cmaj.ca/ lookup/suppl/doi:10.1503/cmaj.151027/-/DC1). Across all survey cycles, $28.8 \%$ of respondents reported receiving a seasonal influenza vaccine in the 12 months before survey participation. The proportion was slightly higher in provinces with a pharmacist policy than in those without a policy (30.4\% v. $28.2 \%)$. The proportion of respondents who reported receiving an influenza vaccine decreased over the study period nationally $(p<0.001)$. Decreases over time were observed in Quebec and Ontario, whereas increases were observed in Nova Scotia, New Brunswick and Alberta (Table 3). We observed notable season-to-season variability in the temporal trends.

Influenza vaccination remained higher in provinces with a pharmacist policy than in those without a policy after we adjusted for potential confounders (adjusted prevalence ratio 1.05, 95\% confidence interval [Cl] 1.02-1.08) (Table 4). We observed no significant interaction of pharmacist policies with age, chronic conditions or income. Respondents in provinces with universal funding for influenza vaccination were more likely than those in provinces without a universal funding policy to report receiving seasonal influenza vaccines (adjusted prevalence ratio 1.13, 95\% Cl 1.101.17), independent of the presence of a pharmacist policy.

Influenza vaccination uptake was positively associated with increased age ( $\geq 50 \mathrm{yr}$ ), female sex, urban residence, high household income, high educational attainment, being married, being of Asian descent, having chronic conditions (except for post-stroke effects), having a higher body mass index, having a child less than 5 years of age in the household, receiving the A/H1N1 2009 pandemic influenza and having a regular doctor (Table 4 and Appendix 2, available at www.cmaj.ca/lookup/suppl/doi:10.1503/cmaj.151027/-/DC1). Uptake was negatively associated with being an immigrant, reporting better health status and daily smoking. Influenza vaccination varied considerably across seasons and provinces.

In the sensitivity analysis, we found no change in the impact of pharmacist policies when we used the $2007 / 08$ or $2008 / 09$ influenza season as the first year of the policy for Alberta.

\section{Interpretation}

During the study period, influenza vaccine coverage declined over time in Canada, but there was substantial interprovincial variability in this trend. Individuals living in provinces with a policy allowing administration of publicly funded influenza vaccines by pharmacists were more likely to report receipt of a seasonal influenza vaccine in the year before survey participation than those living in jurisdictions without a pharmacist policy. Based on the available data capturing the early implementation period of pharmacy poli-

Table 3: Proportion of participants who reported receipt of influenza vaccine within 12 months before survey, by province/territory and influenza season

\begin{tabular}{|c|c|c|c|c|c|c|c|c|c|c|}
\hline Province/territory & $2006 / 07$ & $2007 / 08$ & $2008 / 09$ & $2009 / 10$ & $2010 / 11$ & $2011 / 12$ & $2012 / 13$ & $2013 / 14$ & $p$ value & $\begin{array}{l}\text { Direction } \\
\text { of trend }\end{array}$ \\
\hline $\begin{array}{l}\text { Newfoundland } \\
\text { and Labrador }\end{array}$ & 22.4 & 23.4 & 24.7 & 23.4 & 24.7 & 24.1 & 24.4 & 26.5 & 0.08 & - \\
\hline Prince Edward Island & 32.8 & 28.0 & 26.6 & 26.2 & 30.3 & 32.0 & 27.7 & 34.9 & 0.2 & - \\
\hline Nova Scotia & 40.0 & 39.7 & 37.0 & 43.4 & 47.4 & 43.3 & 40.4 & $44.7^{\star}$ & $<0.001$ & Increase \\
\hline Ontario & 37.5 & 33.6 & 33.5 & 26.9 & 30.6 & 29.4 & $29.7^{\star}$ & $32.9^{\star}$ & $<0.001$ & Decrease \\
\hline Manitoba & 27.6 & 25.1 & 27.3 & 30.5 & 25.9 & 26.1 & 26.7 & 29.6 & 0.2 & - \\
\hline Saskatchewan & 26.8 & 28.1 & 28.4 & 26.5 & 30.2 & 30.5 & 25.2 & 30.4 & 0.2 & - \\
\hline Alberta & 28.0 & 25.7 & 28.6 & $28.5^{\star}$ & $29.3^{*}$ & $26.8^{\star}$ & $27.2^{\star}$ & $30.6^{\star}$ & $<0.001$ & Increase \\
\hline Yukon & 29.2 & 27.4 & 23.6 & 45.3 & 32.7 & 26.8 & 26.8 & 30.0 & 0.8 & - \\
\hline
\end{tabular}


cies for most provinces, the impact of the policies so far has been modest.

Pharmacist policies could conceivably increase influenza vaccination through 3 mechanisms related to accessibility: improved availability, geographic proximity and accommodation. ${ }^{27}$ Large numbers of community pharmacists are available to administer vaccines; for example, $51 \%$ of eligible pharmacists in Ontario ( $n=7358$ ) have been authorized and trained to do so as of $2014 .{ }^{28}$ In addition, most Canadians live close to a pharmacy, thereby possibly increasing physical access to these services. For example, 79\% of the population in Nova Scotia and $91 \%$ of the population in Ontario live within a 5-km driving distance of a community pharmacy. ${ }^{29,30}$ This is particularly important in rural areas, where access to medical or public health services is often limited..$^{9,31}$ Community pharmacies are also accommodating: people can visit during longer hours of operation, often without appointments, and generally experience shorter wait times. ${ }^{7,9,32,33}$ A study in the United Kingdom found that $51 \%$ of patients surveyed who were eligible for free influenza vaccination through a physician preferred instead to pay for the service at a pharmacy because of convenience, and $43 \%$ chose to pay because of ease of access. ${ }^{34}$

Although the results of our study suggest a small impact associated with pharmacist policies, at least during the initial years of implementation, there may be other potential benefits associated with these policies. For instance, enhanced advertising of seasonal influenza vaccination by pharmacies may increase awareness of the important burden of influenza and promote other health-promoting behaviours such as hand-washing and respiratory etiquette, even if it does not necessarily translate to increased influenza vaccine uptake. Because $80 \%$ of Canadians consult with pharmacists, ${ }^{35}$ those who seek nonvaccination services from pharmacists may also receive reminders for annual influenza vaccination. This may be an effective strategy to increase uptake in certain highrisk groups who are less likely to get the vaccine, such as smokers. However, to achieve the intended policy objective of increased vaccine coverage in the population, more promotion of influenza vaccination and further facilitation of vaccine delivery (e.g., vaccinating children at school) may be required in addition to pharmacist policies.

\section{Strengths and limitations}

Our study is novel in assessing the impact of pharmacist policies on influenza vaccination coverage across all Canadian jurisdictions over time. The inclusion of multiple cycles of the Canadian Community Health Survey resulted in a large sample, which allowed us to incorporate many important covariates known to
Table 4: Unadjusted and adjusted prevalence ratios for influenza vaccination

Prevalence ratio $(95 \% \mathrm{Cl})$

\begin{tabular}{|c|c|c|}
\hline Variable & Unadjusted & Adjusted* \\
\hline Presence of pharmacist policy & $1.08(1.06-1.10)$ & $1.05(1.02-1.08)$ \\
\hline Universal funding for influenza vaccines & $1.20(1.18-1.21)$ & $1.13(1.10-1.17)$ \\
\hline \multicolumn{3}{|l|}{ Age group, yr } \\
\hline $12-19$ (ref) & 1.00 (ref) & 1.00 (ref) \\
\hline $20-49$ & $0.91(0.88-0.94)$ & $0.78(0.74-0.81)$ \\
\hline $50-64$ & $1.60(1.55-1.65)$ & $1.18(1.12-1.24)$ \\
\hline$\geq 65$ & $3.05(2.96-3.13)$ & $2.06(1.96-2.17)$ \\
\hline Female sex & $1.24(1.22-1.26)$ & $1.17(1.15-1.19)$ \\
\hline \multicolumn{3}{|l|}{ Province/territory } \\
\hline Newfoundland and Labrador & $1.08(1.03-1.13)$ & $1.01(0.97-1.06)$ \\
\hline Prince Edward Island & $1.32(1.26-1.39)$ & $1.12(1.05-1.18)$ \\
\hline Nova Scotia & $1.87(1.81-1.93)$ & $1.60(1.55-1.66)$ \\
\hline New Brunswick & $1.45(1.41-1.51)$ & $1.33(1.28-1.38)$ \\
\hline Quebec & 1.00 (ref) & 1.00 (ref) \\
\hline Ontario & $1.40(1.37-1.43)$ & $1.21(1.16-1.26)$ \\
\hline Manitoba & $1.22(1.17-1.27)$ & $1.13(1.08-1.18)$ \\
\hline Saskatchewan & $1.26(1.21-1.30)$ & $1.16(1.12-1.21)$ \\
\hline Alberta & $1.25(1.21-1.29)$ & $1.19(1.15-1.24)$ \\
\hline British Columbia & $1.32(1.28-1.36)$ & $1.25(1.21-1.29)$ \\
\hline Nunavut & $1.55(1.45-1.67)$ & $2.54(2.32-2.78)$ \\
\hline Northwest Territories & $1.49(1.41-1.58)$ & $1.88(1.76-2.02)$ \\
\hline Yukon & $1.46(1.29-1.45)$ & $1.36(1.27-1.45)$ \\
\hline \multicolumn{3}{|l|}{ Chronic condition } \\
\hline Asthma & $1.29(1.26-1.32)$ & $1.24(1.21-1.27)$ \\
\hline COPD & $1.64(1.59-1.69)$ & $1.20(1.16-1.23)$ \\
\hline Heart disease & $2.13(2.09-2.18)$ & $1.20(1.17-1.22)$ \\
\hline Stroke & $1.87(1.79-1.95)$ & $1.02(0.98-1.06)$ \\
\hline Diabetes & $2.05(2.01-2.09)$ & $1.25(1.23-1.28)$ \\
\hline Cancer & $1.92(1.86-1.98)$ & $1.15(1.12-1.19)$ \\
\hline Has regular doctor & $2.52(2.43-2.61)$ & $1.67(1.61-1.74)$ \\
\hline \multicolumn{3}{|l|}{ Influenza season } \\
\hline $2006 / 07$ & 1.00 (ref) & 1.00 (ref) \\
\hline $2007 / 08$ & $0.93(0.90-0.96)$ & $0.93(0.91-0.96)$ \\
\hline $2008 / 09$ & $0.94(0.91-0.97)$ & $0.92(0.90-0.95)$ \\
\hline $2009 / 10$ & $0.81(0.78-0.83)$ & $0.91(0.87-0.94)$ \\
\hline $2010 / 11$ & $0.89(0.86-0.92)$ & $0.86(0.84-0.89)$ \\
\hline $2011 / 12$ & $0.87(0.85-0.90)$ & $0.81(0.78-0.84)$ \\
\hline $2012 / 13$ & $0.87(0.84-0.90)$ & $0.79(0.76-0.82)$ \\
\hline $2013 / 14$ & $0.96(0.93-0.99)$ & $0.85(0.82-0.88)$ \\
\hline
\end{tabular}

Note: $\mathrm{Cl}=$ confidence interval, $\mathrm{COPD}=$ chronic obstructive pulmonary disease, ref = reference category. *The multivariable regression model included a sample of 456881 respondents for whom there was complete information on all covariates. In addition to the variables in this table, the model was adjusted for the following: location of residence, household income, educational attainment, marital status, immigration status, racial/cultural group, self-reported health status, category of body mass index, having a child less than $5 \mathrm{yr}$ of age in household, smoking status and receipt of influenza A/H1N1 pandemic vaccine in 2009 (see Appendix 2, available at www.cmaj.ca/lookup/suppl/doi:10.1503/ cmaj.151027/-/DC1). 
be associated with influenza vaccination. It also allowed us to include both pre- and post-policy data from provinces that implemented pharmacist policies.

The major limitation of our study was the unavailability of information on the vaccine provider. We were therefore unable to determine the extent of provider "displacement" (i.e., individuals who previously received the vaccine from a physician or nurse and were now getting it at a pharmacy).

We were also unable to measure the extent to which pharmacists implemented the practice of providing influenza vaccines in provinces that implemented a pharmacist policy. This may have varied by province and duration. The absence of a before-after effect in certain provinces may have been due to underlying temporal trends (e.g., a decrease in coverage over time that may have been mitigated by introduction of a pharmacist policy) or incomplete penetrance of the policy (e.g., in Ontario, not all pharmacists complete the training to administer vaccines and not all pharmacies undergo the approval process that is required to provide influenza vaccines).

Another limitation is the Canadian Community Health Survey's exclusion of important populations, such as children less than 12 years of age and people in institutions, both of which are important groups for influenza vaccination. However, because Canadian pharmacists are not authorized to administer influenza vaccines to children ( $<5 \mathrm{yr}$ of age in some provinces and $<9 \mathrm{yr}$ of age in others) and institutions often have established vaccination programs, these groups may be less likely to obtain the vaccine from pharmacists.

We were also limited by the data available from the Canadian Community Health Survey. Data from the most recent survey period, during which additional provinces implemented a pharmacist policy, are not yet available.

Finally, our study relied on self-report of influenza vaccination status within the 12 months before survey participation, which may be susceptible to reporting biases. However, self-report of influenza vaccination has been shown to be valid ${ }^{36-39}$ and has been used previously to estimate vaccine coverage. ${ }^{23,40,41}$

\section{Conclusion}

The presence of a policy allowing pharmacists to administer publicly funded seasonal influenza vaccines was associated with modest increases in vaccine uptake. Future work to characterize the populations that access this service will aid evaluation efforts and inform decision-making in other jurisdictions that are considering expanding the scope of pharmacist practice to include delivery of vaccines and other services. Ongoing efforts will be needed to evaluate the longer-term impact of pharmacist policies.

\section{References}

1. Kwong JC, Rosella LC, Johansen H. Trends in influenza vaccination in Canada, 1996/1997 to 2005. Health Rep 2007;18:9-19.

2. Santoli JM, Szilagyi PG, Rodewald LE. Barriers to immunization and missed opportunities. Pediatr Ann 1998;27:366-74.

3. Johnson DR, Nichol KL, Lipczynski K. Barriers to adult immunization. Am J Med 2008;121(7 Suppl 2):S28-35.

4. Lester RT, McGeer A, Tomlinson G, et al. Use of, effectiveness of, and attitudes regarding influenza vaccine among house staff. Infect Control Hosp Epidemiol 2003;24:839-44.
5. Kroneman M, van Essen GA, Paget WJ. Influenza vaccination coverage and reasons to refrain among high-risk persons in four European countries. Vaccine 2006;24:622-8.

6. Pharmacists' Scope of Practice Canada. Ottawa: Canadian Pharmacists Association; 2015. Available: www.pharmacists.ca/index.cfm/pharmacy-in-canada/scope -of-practice-canada/ (accessed 2015 Aug. 5).

7. Bowles S, Strang R, Wissmann E. A pilot program of community pharmacy based influenza immunization clinics. Can Pharm J 2005;138:38.

8. Grabenstein JD, Guess HA, Hartzema AG, et al. Attitudinal factors among adult prescription recipients associated with choice of where to be vaccinated. J Clin Epidemiol 2002;55:279-84.

9. Marra F, Kaczorowski J, Gastonguay L, et al. Pharmacy-based Immunization in Rural Communities Strategy (PhICS): a community cluster-randomized trial. Can Pharm J (Ott) 2014;147:33-44.

10. Pharmacist administered vaccines. Washington (DC): American Pharmacists Association; 2015. Available: www.pharmacist.com/sites/default/files/PharmacistlZ Authority.pdf (accessed 2015 Aug. 5).

11. Ernst ME, Chalstrom CV, Currie JD, et al. Implementation of a community pharmacy-based influenza vaccination program. J Am Pharm Assoc (Wash) 1997;NS37:570-80.

12. Ernst ME, Bergus GR, Sorofman BA. Patients' acceptance of traditional and nontraditional immunization providers. J Am Pharm Assoc (Wash) 2001; 41:53-9.

13. Grabenstein JD, Guess HA, Hartzema AG, et al. Effect of vaccination by community pharmacists among adult prescription recipients. Med Care 2001;39:340-8.

14. Steyer TE, Ragucci KR, Pearson WS, et al. The role of pharmacists in the delivery of influenza vaccinations. Vaccine 2004;22:1001-6.

15. Van Amburgh JA, Waite NM, Hobson EH, et al. Improved influenza vaccination rates in a rural population as a result of a pharmacist-managed immunization campaign. Pharmacotherapy 2001;21:1115-22.

16. Usami T, Hashiguchi M, Kouhara $\mathrm{T}$, et al. Impact of community pharmacists advocating immunization on influenza vaccination rates among the elderly. Yakugaku Zasshi 2009;129:1063-8.

17. Most Ontarians would go to their pharmacists for vaccination, survey shows. Toronto: Ontario Pharmacists Association; 2012. Available: https://www.opatoday .com/professional/news/most-ontarians-would-go-to-their-pharmacist-for -immunizations-survey-shows (accessed 2015 July 16).

18. Kau L, Sadowski CA, Hughes C. Vaccinations in older adults: focus on pneumococcal, influenza and herpes zoster infections. Can Pharm J 2011;144:132-41.

19. Canadian Community Health Survey - annual component (CCHS). Ottawa: Statistics Canada; 2014. Available: www23.statcan.gc.ca/imdb/p2SV. pl?Function=getSurvey\&SDDS=3226 (accessed 2015 Jan. 11).

20. Canadian Community Health Survey 2007-2014. Ottawa: Statistics Canada; 2016. Available: www23.statcan.gc.ca/imdb/p2SV.pl?Function=getInstanceList \&ld=238854 (accessed 2016 July 26).

21. Kwong JC, Sambell C, Johansen H, et al. The effect of universal influenza immunization on vaccination rates in Ontario. Health Rep 2006;17:31-40.

22. Kwong JC, Campitelli MA, Rosella LC. Obesity and respiratory hospitalizations during influenza seasons in Ontario, Canada: a cohort study. Clin Infect Dis 2011;53:413-21.

23. Quach S, Hamid JS, Pereira JA, et al.; Public Health Agency of Canada/Canadian Institutes of Health Research Influenza Research Network Vaccine Coverage Theme Group. Influenza vaccination coverage across ethnic groups in Canada. CMAJ 2012;184:1673-81.

24. Thomas S, Wannell B. Combining cycles of the Canadian Community Health Survey. Health Rep 2009;20:53-8.

25. Zou G. A modified poisson regression approach to prospective studies with binary data. Am J Epidemiol 2004;159:702-6.

26. Zhang J, Yu KF. What's the relative risk? A method of correcting the odds ratio in cohort studies of common outcomes. JAMA 1998;280:1690-1.

27. Penchansky R, Thomas JW. The concept of access: definition and relationship to consumer satisfaction. Med Care 1981;19:127-40.

28. 2014 annual report. Toronto: Ontario College of Pharmacists; 2015. Available: www.ocpinfo.com/library/annual-reports/download/Annual\%20Report\%202014. pdf (accessed 2016 July 26).

29. Law MR, Dijkstra A, Douillard JA, et al. Geographic accessibility of community pharmacies in Ontario. Healthc Policy 2011;6:36-46. 
30. Law MR, Heard D, Fisher J, et al. The geographic accessibility of pharmacies in Nova Scotia. Can Pharm J (Ott) 2013;146:39-46.

31. Bearden DT, Holt T. Statewide impact of pharmacist-delivered adult influenza vaccinations. Am J Prev Med 2005;29:450-2.

32. Deshpande M, Schauer J, Mott DA, et al. Parents' perceptions of pharmacists as providers of influenza vaccine to children. J Am Pharm Assoc (2003) 2013; 53:488-95.

33. Papastergiou J, Folkins C, Li W, et al. Community pharmacist-administered influenza immunization improves patient access to vaccination. Can Pharm $J$ (Ott) 2014;147:359-65.

34. Anderson C, Thornley T. "It's easier in pharmacy": why some patients prefer to pay for flu jabs rather than use the National Health Service. BMC Health Serv Res 2014;14:35.

35. 9000 points of care: improving access to affordable healthcare. North York (ON): Canadian Organization of Chain Drug Stores; 2013. Available: 9000pointsofcare.ca/ wp-content/uploads/The-Plan.pdf (accessed 2015 Jan. 12).
36. Hutchison BG. Measurement of influenza vaccination status of the elderly by mailed questionnaire: response rate, validity and cost. Can J Public Health 1989;80:271-5.

37. MacDonald R, Baken L, Nelson A, et al. Validation of self-report of influenza and pneumococcal vaccination status in elderly outpatients. Am J Prev Med 1999;16:173-7.

38. Martin LM, Leff M, Calonge N, et al. Validation of self-reported chronic condi tions and health services in a managed care population. Am J Prev Med 2000;18:215-8.

39. Nichol KL, Korn JE, Baum P. Estimation of outpatient risk characteristics and influenza vaccination status: validation of a self-administered questionnaire. Am J Prev Med 1991;7:199-203.

40. Johansen H, Nguyen K, Mao L, et al. Influenza vaccination. Health Rep 2004; 15:33-43.

41. Polisena J, Chen Y, Manuel D. The proportion of influenza vaccination in Ontario, Canada in 2007/2008 compared with other provinces. Vaccine 2012;30:1981-5
Competing interests: Jennifer Isenor has received grants from the Dalhousie Pharmacy Endowment Fund, the Drug Evaluation Alliance of Nova Scotia and GlaxoSmithKline for research related to vaccination by pharmacists. No other competing interests were declared.

This article has been peer reviewed.

Affiliations: Epidemiology Division (Buchan, Rosella, Kwong), Dalla Lana School of Public Health, University of Toronto; Toronto Public Health (Finkelstein); Institute for Clinical Evaluative Sciences (Juurlink, Kwong), Toronto, Ont.; College of Pharmacy and Faculty of Medicine (Isenor), Dalhousie University, Halifax, NS; Faculty of Pharmaceutical Sciences (Marra) and Faculty of Medicine (Patel), University of British Columbia, Vancouver, BC; Cumming School of Medicine (Russell), University of Calgary, Calgary, Alta.; Public Health Ontario (Rosella, Quach, Kwong), Toronto, Ont.; School of Pharmacy (Waite), University of Waterloo, Waterloo, Ont.
Contributors: Sarah Buchan and Jeffrey Kwong conceptualized and designed the study, interpreted the results and drafted the initial manuscript. Sarah Buchan performed the analyses. Laura Rosella, Michael Finkelstein, David Juurlink, Susan Quach, Margaret Russell and Nancy Waite conceptualized and designed the study, interpreted the results, and critically reviewed and revised the manuscript. Jennifer Isenor, Fawziah Marra and Anik Patel interpreted the results, and critically reviewed and revised the manuscript. All of the authors approved the final version to be published and agreed to act as guarantors of the work.

Funding: Sarah Buchan's doctoral training was supported by a Public Health Agency of Canada/Canadian Institutes of Health Research Influenza Research Network (PCIRN) Trainee Award. Jeff Kwong is supported by a New Investigator Award from the Canadian Institutes of Health Research and a Clinician Scientist Award from the University of Toronto Department of Family and Community Medicine.
Acknowledgement: The authors thank David Haans and Joanna Jacob from the Statistics Canada Data Research Centre at the University of Toronto for their help and guidance.

\section{PCIRN Program Delivery and Evaluation}

Group: Julie Bettinger, David Buckeridge, Jemila Hamid, Natasha Crowcroft, Shelley Deeks, Michael Finkelstein, Maryse Guay, Jeff Kwong, Allison McGeer, Jennifer Pereira, Susan Quach, Sherman Quan and Margaret L. Russell

Accepted: Apr. 22, 2016

Early release: Aug. 8, 2016

Correspondence to: Jeffrey Kwong, jeff.kwong@utoronto.ca 